\title{
Effects of Environmental Factors on Development of Pyrenopeziza brassicae (Light Leaf Spot) Apothecia on Oilseed Rape Debris
}

\author{
T. Gilles, B. D. L. Fitt, and M. J. Jeger
}

First and second authors: Institute of Arable Crops Research, Rothamsted, Harpenden, Herts AL5 2JQ, U.K.; and third author: Wye College, University of London, Ashford, Kent TN25 5AH, U.K.

Current address of T. Gilles: Horticulture Research International, Wellesbourne, Warwick CV35 9EF, U.K.

Accepted for publication 10 January 2001.

\section{ABSTRACT}

Gilles, T., Fitt, B. D. L., and Jeger, M. J. 2001. Effects of environmental factors on development of Pyrenopeziza brassicae (light leaf spot) apothecia on oilseed rape debris. Phytopathology 91:392-398.

The development of Pyrenopeziza brassicae (light leaf spot) apothecia was studied on petiole debris from artificially infected oilseed rape leaves incubated at temperatures from 6 to $22^{\circ} \mathrm{C}$ under different wetness regimes and in $16 \mathrm{~h}$ light $/ 8 \mathrm{~h}$ dark or continuous darkness. There was no significant difference between light treatments in numbers of apothecia that developed. Mature apothecia developed at temperatures from 5 to $18^{\circ} \mathrm{C}$ but not at $22^{\circ} \mathrm{C}$. The rate of apothecial development decreased as temperature decreased from 18 to $5^{\circ} \mathrm{C}$; mature apothecia were first observed after 5 days at $18^{\circ} \mathrm{C}$ and after 15 days at $6^{\circ} \mathrm{C}$. Models were fitted to estimates of the time (days) for $50 \%$ of the maximum number of apothecia to develop $\left(t_{1} ;\right.$ model $\left.1, t_{1}=7.6+55.8(0.839)^{T}\right)$ and the time for $50 \%$ of the maximum number of apothecia to decay $\left(t_{2}\right.$; model $2, t_{2}=24.2+$ $\left.387(0.730)^{T}\right)$ at temperatures $(T)$ from 6 to $18^{\circ} \mathrm{C}$. An interruption in wetness of the petiole debris for 4 days after 4,7 , or 10 days of wetness delayed the time to observation of the first mature apothecia for $\approx 4$ days and decreased the number of apothecia produced (by comparison with continuous wetness). A relationship was found between water content of pod debris and electrical resistance measured by a debris-wetness sensor. The differences between values of $t_{1}$ predicted by model 1 and observed values of $t_{1}$ were 1 to 9 days. Model 2 did not predict $t_{2}$; apothecia decayed more quickly under natural conditions than predicted by model 2 .

Additional keywords: ascoma development, ascospores, Cylindrosporium concentricum, exponential model, forecasting.
Pyrenopeziza brassicae, the cause of light leaf spot on winter oilseed rape, develops apothecia (a discoid ascoma) during its sexual stage on senescent oilseed rape tissues. Apothecia of Pyrenopeziza brassicae have been observed on winter oilseed rape debris in the United Kingdom (17) and Germany (3). Both mating types of Pyrenopeziza brassicae are present in the United Kingdom (4), and sexual reproduction of Pyrenopeziza brassicae is probably frequent in Northwest Europe (21). Mature apothecia have been observed in late summer or autumn on stem and pod debris from harvested crops and in spring on leaf debris under crop canopies $(17,22)$. The wind-dispersed ascospores of Pyrenopeziza brassicae (23) released from apothecia in autumn are thought to cause primary infections that initiate light leaf spot epidemics. This suggestion is supported by the observation that light leaf spot lesions in a crop are randomly distributed early in the season (6). Ascospores released from apothecia on leaf debris under crop canopies in spring are thought to be a cause of infections on stems and pods (11). More information about the conditions that favor maturation of apothecia is needed to improve understanding of the role of Pyrenopeziza brassicae ascospores in light leaf spot epidemics.

There is little information about the effects of environmental conditions on the development of Pyrenopeziza brassicae apothecia. These apothecia develop until they are mature, when their hymenium expands and they release their ascospores; after ascospore release apothecia decay (12). The observation of a reduction

Corresponding author: T. Gilles; E-mail address: Tijs_Gilles@hotmail.com

Publication no. P-2001-0221-01R

This article is in the public domain and not copyrightable. It may be freely reprinted with customary crediting of the source. The American Phytopathological Society, 2001. in numbers of airborne ascospores of Pyrenopeziza brassicae following periods of dry weather (22) suggests that less apothecia mature under dry conditions and that wetness is required for development of Pyrenopeziza brassicae apothecia. There is also evidence that the amount of rainfall affects the development of apothecia of Sclerotinia sclerotiorum (Sclerotinia stem rot) on oilseed rape debris in Sweden (24) and Pseudopezicula tracheiphila ("rotbrenner" on grape) on grapevine leaf debris (30). Because wetness is an important factor affecting apothecial development, an accurate method to measure wetness is essential to improve understanding of apothecial development. Most commonly measurements of rainfall or relative humidity $(5,14,16,24$, $28,30,34)$ have been used in studies on apothecial development, but measurements of wetness of debris are actually needed. A debris-wetness sensor has been developed that indicates when debris is wet by measurements of electrical resistance through debris (22). Electrical resistance is related to water content (7), therefore, such a debris-wetness sensor could be used to determine periods of wetness of debris by relating electrical resistance to water content of oilseed rape debris.

Temperature and light may also affect development of Pyrenopeziza brassicae apothecia. Effects of temperature on apothecial development have been demonstrated for Whetzelinia sclerotiorum (white mold on phaseolus beans); apothecia did not develop from sclerotia outside upper or lower temperature thresholds (1). Temperature also affected the rate of apothecial development and length of time when mature apothecia of Blumeriella jaapii (cherry leaf spot) were present on senesced cherry leaves (9). Light was essential for the development of apothecia of $S$. trifoliorum (29). This paper reports the effects of temperature, interrupted wetness, and light on the maturation and decay of apothecia of Pyrenopeziza brassicae on oilseed rape debris, and the de- 
velopment of a method to determine lengths of periods for which debris was wet. Furthermore, the effects of temperature on apothecial development and decay are described in models that are tested with data on apothecial development obtained under natural conditions in a field plot.

\section{MATERIALS AND METHODS}

Effects of light, temperature, and wetness on the development of apothecia. Apothecia were produced on leaf petiole debris collected after senescence of oilseed rape (cv. Bristol) leaves inoculated with Pyrenopeziza brassicae isolate RES97 according to the method described by Gilles et al. (13). After collection, the petioles were dried in air at $20^{\circ} \mathrm{C}$ for 1 day and kept dry for 2 days before being soaked in rain water for $16 \mathrm{~h}$. The wetted petioles were placed in plastic boxes $(12.5 \times 8 \mathrm{~cm})$ with seven petioles per box on three layers of filter paper (Whatman No. 1; Whatman International Ltd., Maidstone, England) that had been wetted with $7 \mathrm{ml}$ of rain water. Under these conditions, free water surrounded the petioles, which were, therefore, considered wet. However, actual measurements of water content were not done. To test the effects of light on the development of mature apothecia, one box with petioles was incubated in a controlled environment cabinet at $16^{\circ} \mathrm{C}\left(+1.5^{\circ} \mathrm{C}\right.$ during the light period) with a daily regime of $16 \mathrm{~h}$ light/8 h dark $\left(190 \mu \mathrm{E} \mathrm{m}^{-2} \mathrm{~s}^{-1}\right.$ light intensity, fluorescent and tungsten lighting) and another box was incubated in the same cabinet in continuous darkness inside an enclosed box. The number of mature apothecia per length of petiole was counted by observing the petioles through a binocular dissecting microscope (Olympus Optical Co., London) at $\times 14$ magnification after 25 days of incubation. Apothecia were recorded as mature when the light gray hymenium was visible, because previous observations of developing apothecia suggested that ascospores are released at this stage (10). The experiment was performed three times.

Effects of temperature on the development of mature apothecia of Pyrenopeziza brassicae were tested on artificially infected petioles and on naturally infected half pods that were collected on 30 July after harvest of a winter oilseed rape crop at Rothamsted, U.K. The infected petioles were incubated on wet filter paper in the plastic boxes in temperature-controlled rooms at $6.0(5.8$ to 6.2 $)^{\circ} \mathrm{C}, 9.2(9.1 \text { to } 9.9)^{\circ} \mathrm{C}, 12.9(12.0 \text { to } 13.5)^{\circ} \mathrm{C}, 17.1(16.7$ to $17.4)^{\circ} \mathrm{C}, 18.2(17.7 \text { to } 18.4)^{\circ} \mathrm{C}$, or $22.3(21.9 \text { to } 22.7)^{\circ} \mathrm{C}$. At each temperature, apothecial development was observed on the experimental unit of five boxes containing four petioles (i.e., on 20 petioles). Apothecial development was assessed on these 20 petioles by counting the number of mature apothecia per length of petiole after different times of incubation. The experiment was performed twice. The naturally infected half pods were incubated in the same way in temperature-controlled rooms at $5.4(5.0 \text { to } 5.8)^{\circ} \mathrm{C}, 6.4(6.2$ to $6.9)^{\circ} \mathrm{C}, 10.6(10.2 \text { to } 10.6)^{\circ} \mathrm{C}$, or $17.1(17.0 \text { to } 17.7)^{\circ} \mathrm{C}$. At each temperature, apothecial development was observed on an experimental unit of one box containing 20 half pods. The experiment was performed three times. The total number of apothecia on 20 half pods was counted every 2 to 5 days.

The effects of an interruption in wetness on the development of Pyrenopeziza brassicae apothecia were tested on artificially infected petioles incubated in plastic boxes on wet filter paper (previously described) in a temperature-controlled room at $12.9(12.0 \text { to } 13.5)^{\circ} \mathrm{C}$. After 4,7 , or 10 days of wetness, an experimental unit of three boxes containing 20 petioles per box was taken out of the temperature-controlled room. The lids were taken off the boxes, and the boxes were placed in an air-flow cabinet (Microflow Ltd., Fleet, U.K.) for $3 \mathrm{~h}$ to dry the petioles. The boxes were then closed and placed in the temperature-controlled room at $12.9^{\circ} \mathrm{C}$, and after 4 days the dried petioles were wetted again by adding $15 \mathrm{ml}$ of rain water to the filter paper in each box. Petioles were kept under continuous wetness as a control treatment. The number of apothecia per length of petiole was counted after different times of incubation. This experiment was performed three times, and each treatment was applied randomly to the experimental unit of three boxes in each experiment.

Modeling effects of temperature on maturation of apothecia. The data for changes with time in numbers of apothecia of Pyrenopeziza brassicae per length of petiole at 6.0, 9.2, 12.9, 17.1 , or $18.2^{\circ} \mathrm{C}$ and for changes with time in numbers of apothecia per 20 pods at $5.4,6.4,10.6$, or $17.1^{\circ} \mathrm{C}$ were used to construct a temporal model describing the occurrence of mature apothecia as a function of temperature. From these data, the times until the number of apothecia had increased to $50 \%$ of the maximum number of apothecia $\left(t_{1}\right)$ and until the number of apothecia had subsequently decreased to $50 \%$ of the maximum $\left(t_{2}\right)$ were calculated. When the times of $t_{1}$ or $t_{2}$ were between two dates on which the numbers of apothecia had been counted, linear interpolation was used to estimate their values. With the statistical software Genstat 5 (release 4.1; Numerical Algorithms Group Ltd., Oxford), an exponential function of the form

$$
t_{1}=a+b r^{T}(0<r<1)
$$

with parameters $a$ ( $t_{1}$ asymptote), $b$ ( $a+b$ is the longest time to apothecial development at $0^{\circ} \mathrm{C}$ ), and $r$ (decrease in time to apothecial development with increasing temperature) was fitted to the estimates of $t_{1}$ (in days) to describe the effects of temperature ( $T$ in degrees Celsius) on development of mature apothecia (model 1 ). The same function was also fitted to the estimates of $t_{2}$ (in days) to describe the effects of temperature on the time to $50 \%$ decay of apothecia (model 2).

Method to measure wetness of pod debris. A method was developed to determine when pod debris is wet by measuring electrical resistance through the debris. To measure the electrical resistance of pod debris, a device was made of two $10-\times 8-\mathrm{cm}$ epoxy glass laminate boards coated with copper (RS Components, Corby, U.K.) from which two $2.5-\times 5-\mathrm{cm}$ sections were cut out (Fig. 1), similar to one used in a previous study (22). On the two shorter sides of the cut-out sections, the copper was removed, leaving three strips of copper across the width of the boards. Where the copper was removed, the boards were coated with wax to prevent capillary flow of water between the strips of copper. Two boards were fixed on top of each other with bolts, and between these boards oilseed rape debris (12 half pods) were clamped so they made contact with the copper strips at both ends. An excitation pole of $5,000 \mathrm{mV}\left(V_{x}\right)$ from a data logger (21X Micrologger; Campbell Scientific Ltd., U.K.) was connected via a $15-\mathrm{k} \Omega$ reference resistor $\left(R_{f}\right)$ to the central copper strip on this pod debris-wetness sensor. The copper strips at both ends of the sensor were connected to the earth of the data logger (half bridge electrical circuit). The residual voltage from the pod debris-wetness sensor $\left(V_{s}\right)$ was measured in relation to the excitation voltage $\left(V_{x}\right)$ as $x\left(=V_{s} / V_{x}\right)$, recorded by the data logger and used to calculate the electrical resistance of the sensor $\left(R_{s}\right)$ with the equation $R_{s}=$ $x R_{f} / 1-x$. However, to estimate when pod debris was wet, it was necessary to relate the electrical resistance to the water content of the pod debris.

To study the relationship between the water content of 12 half pods and the electrical resistance of the debris-wetness sensor, half pods were collected on 30 July 1999 from the ground after harvest of a winter oilseed rape crop (cv. Bristol) at Rothamsted, U.K. which had been severely affected by light leaf spot. They were wetted in distilled water for $1 \mathrm{~h}$. Excess surface water on these half pods was then removed with absorbent paper, before the half pods were clamped into four pod debris-wetness sensors (12 half pods per sensor), which were connected to a data logger. At $\approx 5$-min intervals, the debris-wetness sensors were disconnected and their weight was measured on a balance (Model AT100; Mettler-Toledo Limited, Leicester, U.K.). After each weight measurement, the sensors were reconnected to the data logger and their 
electrical resistance was measured. These measurements continued until the measured resistance was greater than $8 \times 10^{4} \mathrm{k} \Omega$. The dry weights of the four sets of 12 half pods and the dry weights of the four sensors without the half pods were then measured, and these measurements were used to calculate the water content of the four sets of 12 half pods during the experiment. These measurements were repeated once with four different sets of 12 half pods collected after harvest of the crop. The function

$$
\log R=c+d f^{\log (1-W)} \quad(0 \leq W \leq 1)
$$

with parameters $c$ ( $\log R$ asymptote), $d(c+d$ is the maximum $\log$ $R$ value when debris is completely dry, $W=0$ ), and $f$ (decrease in $\log R$ for increasing $\log (1-W))$ was fitted to describe the relationship between electrical resistance ( $R$, measured in kilo Ohm) and water content of 12 half pods ( $W$, measured in grams of water per grams of total weight). The data for $R$ and $1-W$ (values of $W$ increased from 0 to an asymptote at 1 , complete saturation of debris with water) were log-transformed to normalize the residuals. With this equation, the water content of the 12 half pods in the sensor was estimated from the measured electrical resistance through the debris-wetness sensor. An arbitrary threshold water content was chosen, below which electrical resistance increased greatly. Pod debris was considered dry below this threshold water content and wet above this threshold water content.

Field test of the model. Naturally infected pod debris collected on 30 July 1999 after harvest of the winter oilseed rape crop at
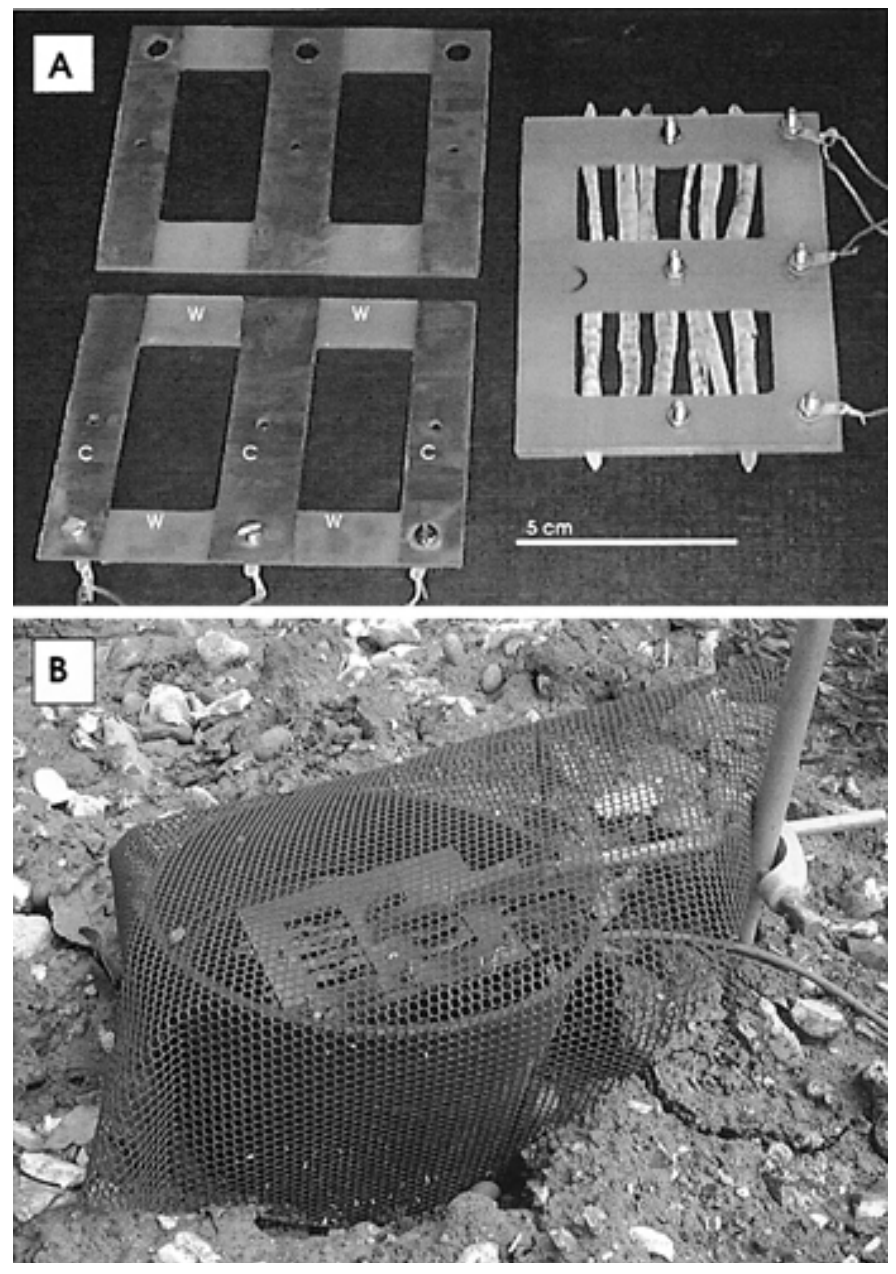

Fig. 1. A, A debris-wetness sensor made from two epoxy glass laminate boards coated with three strips of copper (C), set up to measure the resistance of 12 half pods (scale bar $5 \mathrm{~cm}$ ) and $\mathbf{B}$, operating in field conditions. Between the strips of copper, the boards were coated with wax (W) to prevent capillary flow of water to make contact between these strips.
Rothamsted was dried at $20^{\circ} \mathrm{C}$ for 2 days and stored at $4^{\circ} \mathrm{C}$. At seven different times during the autumn/winter of the 1999/2000 season, two trays $(22 \times 16.5 \mathrm{~cm}, 8 \mathrm{~cm}$ deep with four holes in the bottom of each tray to drain the excess water) covered with plastic netting (mesh size $3 \times 3 \mathrm{~mm}$, to prevent pods from being blown away by wind) and containing 30 half pods were placed on the ground of a field plot at the Institute of Arable Crops Research (Rothamsted, U.K.). The numbers of mature apothecia on this debris exposed outdoors were counted under a binocular dissecting microscope at $\times 14$ magnification in the laboratory at regular intervals from 19 November 1999 until 3 May 2000. As a control (to determine the ability of these pods to produce mature apothecia), some of this pod debris was incubated in a temperature-controlled room at $12.9(12.0 \text { to } 13.5)^{\circ} \mathrm{C}$ in plastic boxes on wetted filter paper at the same time as pod debris was placed in trays outdoors.

In the field plot, four debris-wetness sensors with 12 half pods clamped to each sensor were placed in pots covered with netting (mesh size $3 \times 3 \mathrm{~mm}$ ) and half-buried in the ground to create conditions comparable with those of the pod debris half-buried in the trays covered with netting (Fig. 1B). The electrical resistance of the wetness sensors was measured every $10 \mathrm{~min}$, and hourly averages were recorded with a micrologger. Hourly measurements of temperature were made with a temperature data logger (Tinytalk II; Gemini Data Loggers Ltd., Chichester, U.K.). Hourly rainfall data were obtained from the Rothamsted meteorological station that was $50 \mathrm{~m}$ from this field plot.

To test the relationships between temperature $(T)$ and $t_{i}$ described in models 1 and 2, the equations were modified to give hourly rate functions $1 / t_{i, h}=1 /\left\{24\left[a+b(r)^{T}\right]\right\} ;(0<r<1)$. Hourly average temperatures $(T)$ were input into these equations to predict the hourly rates of apothecial development $\left(1 / t_{1}\right)$ or hourly rates of apothecial decay $\left(1 / t_{2}\right)$. A rate function was chosen so periods $t_{1}$ or $t_{2}$ could be calculated under fluctuating temperatures.

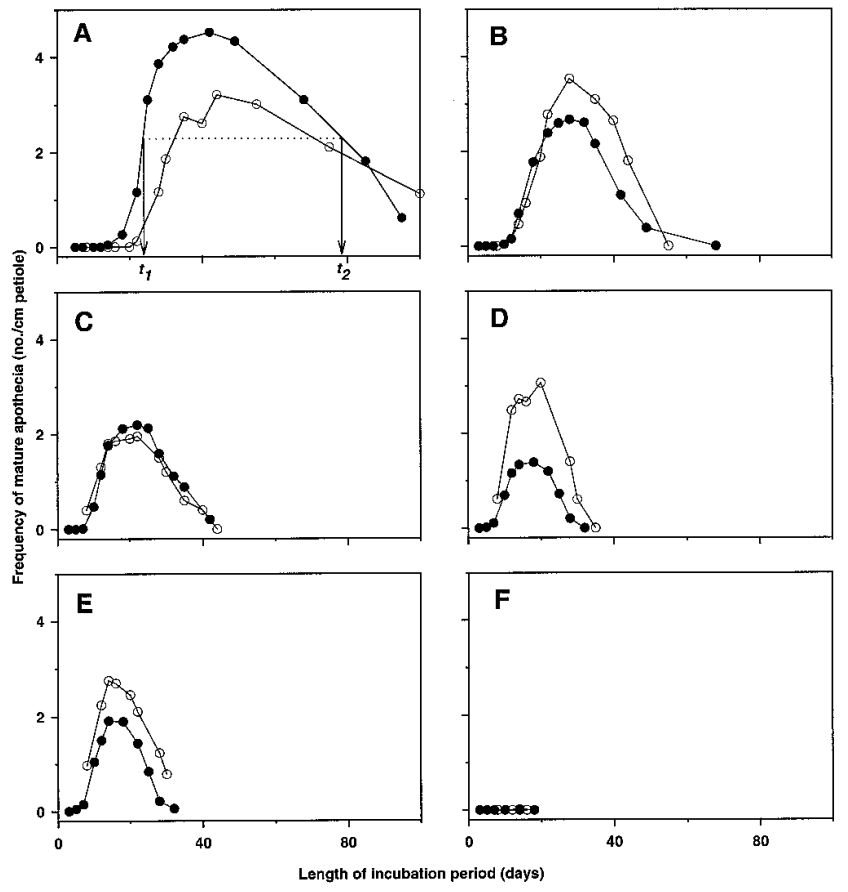

Fig. 2. Numbers of mature apothecia of Pyrenopeziza brassicae (light leaf spot) per length of oilseed rape leaf petiole debris (in centimeters) after different times of incubation under continuous wetness at $\mathbf{A}, 6.0 ; \mathbf{B}, 9.2 ; \mathbf{C}$, 12.9 ; D, 17.1; E, 18.2; and $\mathbf{F}, 22.3^{\circ} \mathrm{C}$ in two experiments $(\circ, \bullet)$. The leaf petiole debris was obtained from artificially infected oilseed rape plants (cv. Bristol). Arrows indicate how the times to $50 \%$ apothecial maturation $\left(t_{1}\right)$ or to $50 \%$ apothecial decay $\left(t_{2}\right)$ were estimated by linear interpolation between observations of numbers of mature apothecia. 
The effects of temperature on apothecial development were assumed to be additive. Therefore, these hourly rate values were summed over periods when the pod debris was wet and temperature was above $0^{\circ} \mathrm{C}$ until the value 1 was reached, which was at times $t_{1}$ or $t_{2}$, respectively.

$$
\sum_{i=0}^{t=t_{i}}\left(1 / t_{i, h}\right)=1 \quad(i=1,2)
$$

It was assumed that the apothecia of Pyrenopeziza brassicae did not continue to develop or decay when the pod debris-wetness sensor measurements suggested that the debris was dry or when temperature was $<0^{\circ} \mathrm{C}$. The values of $t_{1}$ and $t_{2}$ predicted by models 1 and 2 , respectively, were compared with values of $t_{1}$ and $t_{2}$ observed during the development of mature apothecia on pod debris. The errors in prediction of $t_{1}$ or $t_{2}$ were compared with the errors in prediction when an average of observed values of $t_{1}$ or $t_{2}$ was used. A Student's $t$ test was used to test whether the errors in the model predictions were smaller than the errors in prediction by using average values of $t_{1}$ or $t_{2}$.

\section{RESULTS}

Effects of light, temperature, and wetness on the development of apothecia. Under alternating $16 \mathrm{~h}$ light/ $8 \mathrm{~h}$ darkness, an average of 2.30 apothecia per $\mathrm{cm}$ length of petiole was produced; whereas in continuous darkness, an average of 2.27 apothecia per $\mathrm{cm}$ of petiole was produced. Thus, the number of apothecia produced in alternating light/dark conditions did not differ significantly from the number produced in continuous darkness $($ sed $=$ 0.796 , df $=2$ ). Mature apothecia developed under continuous wetness at temperatures from 5.4 to $18.2^{\circ} \mathrm{C}$ but not at $22.3^{\circ} \mathrm{C}$ (Fig. 2). The length of the period of wetness required until the first mature apothecia were observed increased from 5 to 15 days when temperature decreased from 18.2 to $5.4^{\circ} \mathrm{C}$. Furthermore, the time period over which mature apothecia were observed (i.e., from the first to the last apothecia) increased from 27 to 90 days when temperature decreased from 18.2 to $5.4^{\circ} \mathrm{C}$.

When a 4-day interruption in wetness was applied after 4 or 7 days of continuous wetness at $12.9^{\circ} \mathrm{C}$, mature apothecia were first observed after 14 days of incubation (Fig. 3). When the 4-day interruption in wetness was applied after 10 days of wetness,

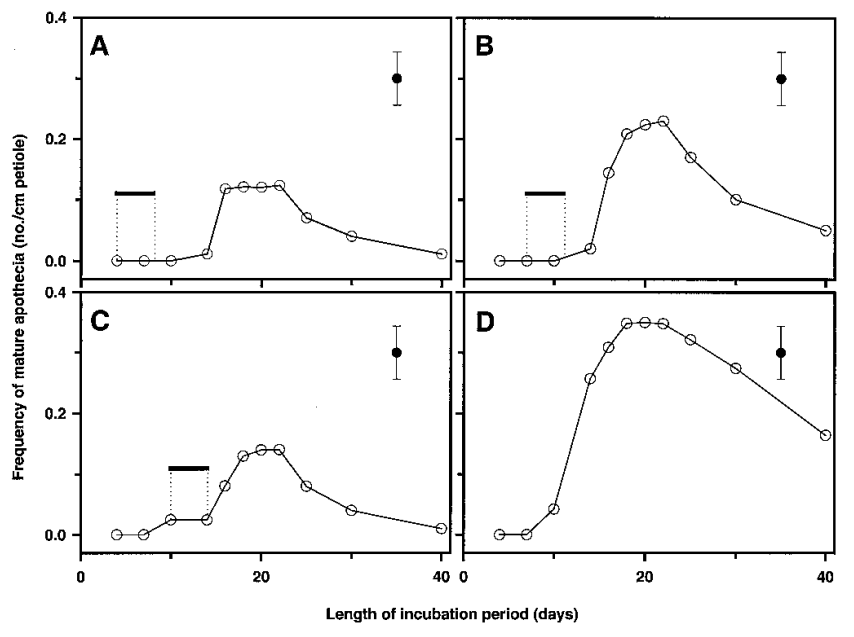

Fig. 3. Changes with time in numbers of mature apothecia of Pyrenopeziza brassicae per length of oilseed rape leaf petiole debris (in centimeters) that received a 4-day interruption (-) in continuous wetness after $\mathbf{A}, 4 ; \mathbf{B}, 7$; and C, 10 days of wetness or $\mathbf{D}$, under continuous wetness at $12.9^{\circ} \mathbf{C}$. The leaf petiole debris was obtained from artificially infected oilseed rape plants (cv. Bristol). Data points denote estimated mean values (three experiments). Vertical error bars are the standard errors of the differences between mean values (52 df). mature apothecia had already been observed. Under continuous wetness, mature apothecia were first observed after 10 days of incubation. The maximum number of mature apothecia occurred after 18 to 22 days of incubation for all treatments, except where there was a 4-day interruption in wetness after 4 days of wetness; in this case, the maximum occurred after 16 to 22 days of incubation. After a 4-day interruption in wetness, fewer mature apothecia developed than when petioles were incubated under continuous wetness.

Modeling effects of temperature on maturation of apothecia. Equation 1 was fitted to the data for $t_{1}$ (in days) or $t_{2}$ (in days) to obtain parameter estimates (with standard errors) for models 1 and 2

$$
\begin{aligned}
t_{1}= & 7.6+55.8(0.839)^{T} \\
& (1.76) \quad(8.37)(0.0310) \\
t_{2}= & \underset{1.43) \quad(51.8)(0.0185)}{24.2+387}(0.730)^{T}
\end{aligned}
$$

(model 1)

(model 2)

describing the effects of temperature on the times when $50 \%$ of apothecia have reached maturity $\left(t_{1} ;\right.$ model 1$)$ or when $50 \%$ of apothecia had decayed $\left(t_{2} ;\right.$ model 2$)$. Models 1 and 2 fitted well to the data and accounted for $95.1 \%(P<0.001)$ and $98.8 \%(P<$ 0.001 ) of the variance, respectively (Fig. 4). The difference between $t_{1}$ and $t_{2}$, an estimate of the length of time when mature apothecia were present, increased when temperature decreased from 18.2 to $5.4^{\circ} \mathrm{C}$

A method to measure wetness of pod debris. Equation 2 was fitted to describe the relationship between data for electrical resistance through debris $(R)$ and water content of the 12 half pods in the sensor $(W)$ as $\log R=3.29+24.09(52.69)^{\log (1-W)}$. This equation described the relationship well and accounted for $93 \%$ of the variance in the data $(P<0.001)$ (Fig. 5). An arbitrary water content of $0.35 \mathrm{~g}$ of water per $\mathrm{g}$ of total weight was chosen, below which electrical resistance increased greatly. Pod debris was considered wet when water content was above this threshold value, and thus, measured electrical resistance was below $2.1 \times 10^{3} \mathrm{k} \Omega$.

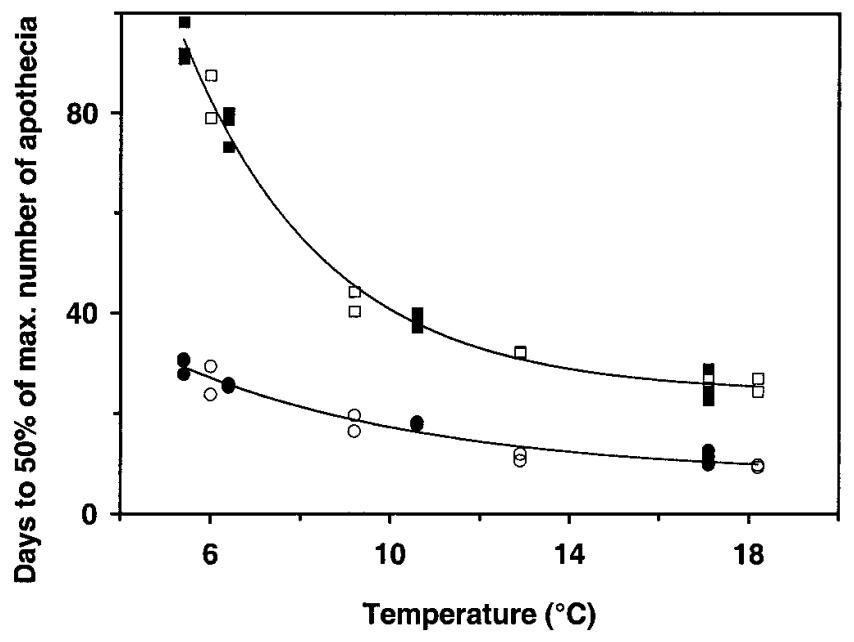

Fig. 4. Modeling effects of temperature on days of incubation until the number of mature apothecia of Pyrenopeziza brassicae had increased to $50 \%$ of the maximum $\left(t_{1}, \circ, \bullet\right)$ and until the number had subsequently decreased to $50 \%$ of the maximum $\left(t_{2}, \square, \boldsymbol{\square}\right)$ on oilseed rape petiole debris from artificially inoculated leaves (cv. Bristol) $(O, \square)$ or on naturally infected pod debris from a winter oilseed rape $\operatorname{crop}(\bullet,-\mathbf{)})$. From the observed data for the numbers of apothecia, $t_{1}$ or $t_{2}$ were estimated by linear interpolation between observations on two successive times when numbers were above and below $50 \%$ of the maximum number of apothecia. Exponential functions (lines) were fitted to describe the relationship between these estimates for $t_{1}\left(t_{1}=7.6\right.$ $+55.8(0.839)^{T}$; model 1 accounted for $95.1 \%$ of the variance in the data $[P<$ $0.001])$ and $t_{2}\left(t_{2}=24.2+387(0.730)^{T}\right.$; model 2 accounted for $98.8 \%$ of the variance in the data $[P<0.001])$ with temperature $(T)$. 
Field test of the model. Predictions of $t_{1}$ by model 1 agreed well with observed $t_{1}$ for short $t_{1}$ periods of 37 to 45 days (error in prediction is 1 to 2 days), but model 1 overpredicted $t_{1}$ for longer $t_{1}$ periods of 49 or 50 days (error in prediction is 4 to 9 days) (Fig. 6 ). The errors in prediction of $t_{1}$ by model 1 were not significantly smaller than the errors when $t_{1}$ was predicted by using an average of 45 days for $t_{1}$, which was calculated from observed $t_{1}$ periods (Table 1). Model 2 considerably overpredicted $t_{2}$ throughout the experiment (by 48 to 71 days). The error in prediction of $t_{2}$ by model 2 was, therefore, significantly greater than the error in prediction by using an average value of 65 days for $t_{2}$ calculated from observed $t_{2}$ periods. The numbers of mature apothecia observed on the pod debris placed outdoors on 19 November, 26 November, and 10 December 1999 decreased greatly between 31 January and 8 February 2000 (Fig. 7). A heavy rain shower occurred during the night of 1 to 2 February, and the pod debris wetness greatly decreased on 8 February 2000. During periods when there was frequent wetting and drying of the pod debris (e.g., 8 to 26 February 2000), the numbers of mature apothecia observed were much smaller than during periods of more continuous wetness (e.g., 4 to 25 January 2000). The pod debris that was incubated under continuous wetness at $12.9^{\circ} \mathrm{C}$ at the same time that pod debris was placed outdoors produced large numbers of apothecia. Thus, the pod debris was capable of producing mature apothecia at all times during the experiment.

\section{DISCUSSION}

The results of current studies under controlled conditions suggest that temperature can inhibit maturation of apothecia of Pyrenopeziza brassicae on oilseed rape debris. They provide evidence that apothecia do not mature at temperatures above $22^{\circ} \mathrm{C}$, a similar upper limit to that for apothecia of $S$. trifoliorum $\left(25^{\circ} \mathrm{C}\right)$ (29) or B. jaapii $\left(24^{\circ} \mathrm{C}\right)(9)$. However, the lower limiting temperature for Pyrenopeziza brassicae apothecial maturation was not confirmed, although it may be similar to that for apothecia of $B$. jaapii $\left(4^{\circ} \mathrm{C}\right)(9)$. Furthermore, the results suggest that the rates of both maturation and decay of apothecia of Pyrenopeziza brassicae are affected by temperature, with apothecia maturing and decaying more rapidly at higher temperatures and mature apothecia persisting longer on debris at lower temperatures. Pseudothecia of Pleospora allii (anamorph Stemphylium vesicarium) on garlic leaf

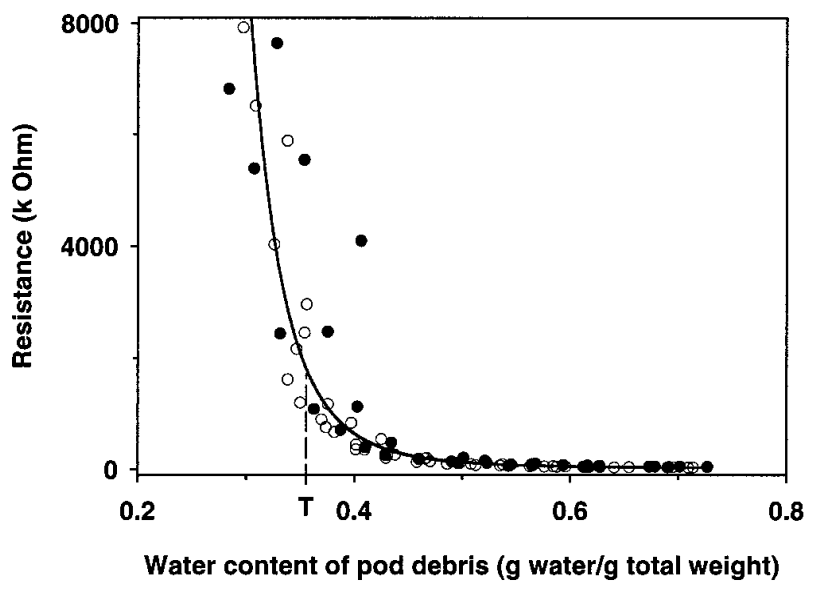

Fig. 5. The electrical resistance $(R)$ of oilseed rape pod debris (12 half pods) measured by a debris-wetness sensor (in kilo Ohm) in relation to their water content ( $W$, in grams of water per gram of total weight). The data were obtained from measurements with four wetness sensors during an experiment $(\circ)$ that was repeated with different pods $(\bullet)$. A function (line; $\left.\log R=3.29+24.09(52.69)^{\log (1-W)}\right)$ accounting for $93 \%$ of the variance in the data $(P<0.001)$ was fitted to these data. Debris was considered dry when its water content was below a threshold (T) of $0.35 \mathrm{~g}$ of water per $\mathrm{g}$ of total weight. debris also decayed more quickly at higher temperatures (28). Detailed studies of pseudothecial development of Venturia inaequalis found that the optimum temperature differs between different stages in development like pseudothecial initiation, ascogonial formation, maturation of asci, and ascospore formation; as pseudothecial development progressed the optimum temperature increased (25). Whether optimal temperature changes similarly during development of Pyrenopeziza brassicae apothecia requires investigation.

The experiments in which incubated petioles were exposed to a 4-day interruption in wetness suggest that intermittent dry periods delay the maturation of Pyrenopeziza brassicae apothecia, probably because the rate of apothecial development within dry debris is very small and decrease the number of mature apothecia produced. A delay in maturation of ascomata was also found for other ascomycetes. Intermittent dry periods delayed maturation of perithecia of Guignardia citricarpa (citrus black spot) on senesced citrus leaves (19) and the maturation of apothecia of S. sclerotiorum on sclerotia in the soil (34). This conclusion is further supported by the observations on Pyrenopeziza brassicae apothecial development on pods exposed outdoors in current work. Smaller numbers of apothecia were observed from 8 to 26 February 2000 , when the pod debris was frequently dry, than in the period from 4 to 25 January 2000, when the debris was almost continuously wet. Under controlled conditions, no evidence was found that light affects the development of Pyrenopeziza brassicae apothecia on debris, but this does not exclude a possible effect
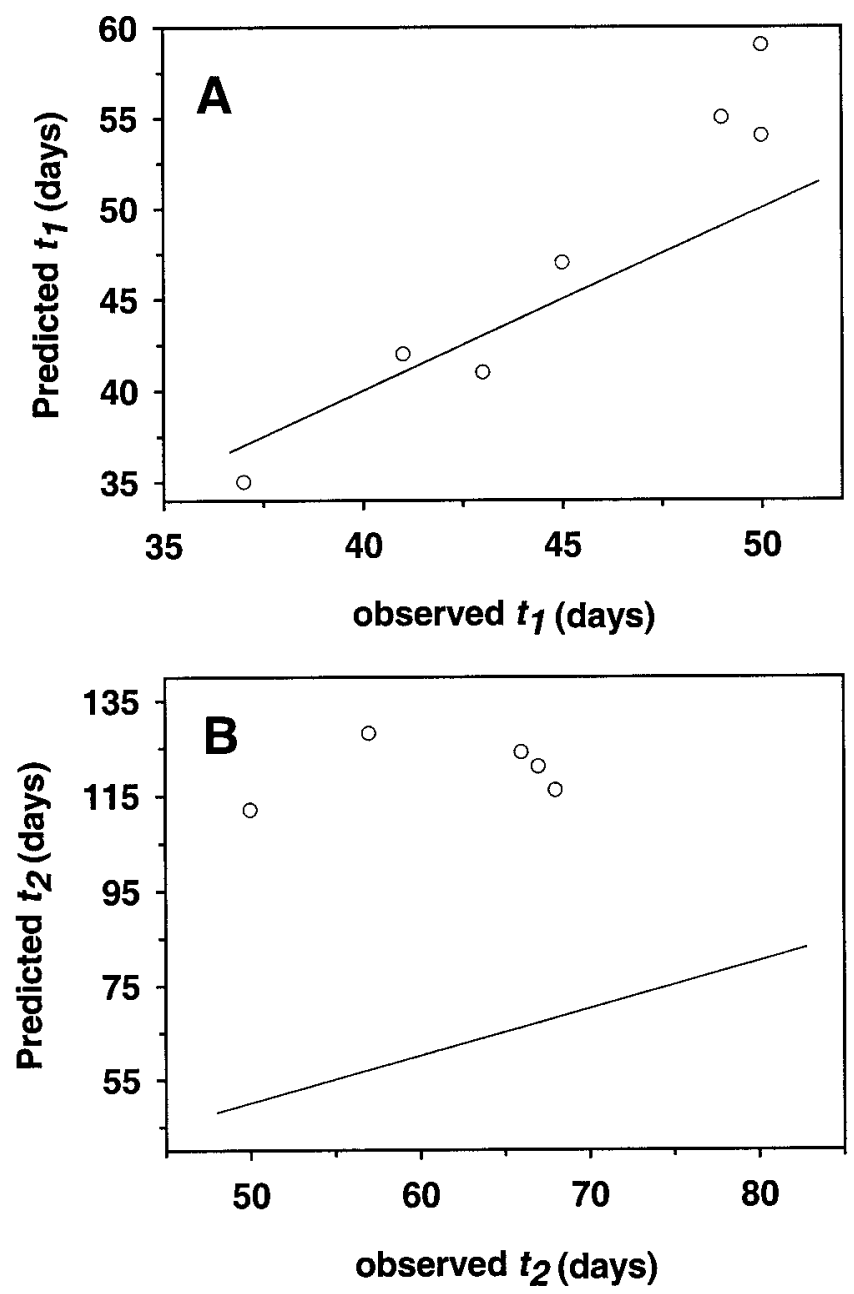

Fig. 6. A, Predicted values of the times until $50 \%$ of apothecia of Pyrenopeziza brassicae had matured $\left(t_{1}\right)$, or $\mathbf{B}, 50 \%$ of apothecia had decayed $\left(t_{2}\right)$ in comparison with observed values of $t_{1}$ or $t_{2}$. The values predicted by the model of $t_{1}$ or $t_{2}(0)$ are compared with the observed values (solid line). 
of day length or exposure to light of Pyrenopeziza brassicae on living oilseed rape tissues prior to tissue senescence, because apothecial development may be initiated directly after infection of living tissues (10). Furthermore, certain wavelengths of light may inhibit or enhance apothecial development as was found for $S$. sclerotiorum (31).

The results of the work developing a method to measure periods when debris was wet suggest that the debris-wetness sensor can be used to determine water content, because there was a good relationship between the electrical resistance and the water content of oilseed rape pod debris. Debris could be defined as being wet when its water content was above a certain threshold, which allowed development of Pyrenopeziza brassicae ascoma. Previous studies have shown that fungal development can cease when the water content is below a certain threshold value. Lesions of Phytophthora cinnamomi on stems of Eucalyptus marginata ceased their extension when the relative water content was $<85 \%$ (33), and mycelial growth and sporulation of Penicillium roquefortii on buckwheat seeds ceased when the relative water content was close to $40 \%$ (18). In studies on fungal growth in alfalfa hay the threshold relative water content for ascoma development (28 to $42 \%$ ) was lower than that for mycelial development (52 to $65 \%$ ) of fungi in the hay (2). Although the threshold relative water content selected for Pyrenopeziza brassicae (35\%) fits with these findings, further work is needed to determine experimentally the threshold water content for development of Pyrenopeziza brassicae apothecia. This would improve the method to determine periods of wetness with the sensor.

The test of the models under natural conditions to evaluate the effects of temperature on Pyrenopeziza brassicae apothecial development during periods of wetness suggests that model 1 may predict $t_{1}$ well for short periods ( $t_{1}<45$ days) but not for longer periods, and that model 2 greatly overpredicted $t_{2}$. Model 1 may have sometimes overpredicted $t_{1}$ because apothecia continued their development at debris water contents below the threshold selected. Clearly, model 2 did not satisfactorily predict apothecial decay under natural conditions, which indicates that it did not account for all factors affecting apothecial decay. Perhaps an early occurrence of conditions that stimulate ascospore release, such as wetting and drying of debris (22), causes early apothecial decay. Furthermore, antagonistic microorganisms occurring under natural conditions might enhance Pyrenopeziza brassicae apothecial decay because antagonists increased decay of B. jaapii and S. sclerotiorum apothecia $(20,27)$. We recognize that the obtained relationships in models 1 and 2 are based on controlled environment experiments with only limited testing under natural conditions. The similarity between observed and predicted values of $t$ may be specious, but this problem can be addressed by continuing checks

TABLE 1. Observed and predicted times to 50\% development of Pyrenopeziza brassicae apothecia $\left(t_{1}\right.$; in days) and to $50 \%$ decay of apothecia ( $t_{2}$; in days) on naturally infected oilseed rape pod debris placed in a field plot at the Institute of Arable Crops Research (Rothamsted, U.K.) at different times during the autumn and winter of the 1999/2000 season

\begin{tabular}{lcccc}
\hline Onset & Observed $t_{1}$ & Predicted $t_{1}$ & Observed $t_{2}$ & Predicted $t_{2}$ \\
\hline $19 \mathrm{Nov}$ & 41 & 42 & 68 & 116 \\
$26 \mathrm{Nov}$ & 45 & 47 & 67 & 121 \\
$3 \mathrm{Dec}$ & 49 & 55 & 66 & 124 \\
$10 \mathrm{Dec}$ & 43 & 41 & 57 & 128 \\
$7 \mathrm{Jan}$ & 37 & 35 & 50 & 112 \\
$1 \mathrm{Feb}$ & 50 & 59 & 82 & $*$ *a \\
$17 \mathrm{Feb}$ & 50 & 54 & 68 & $*$ \\
& $t_{12}=0.20^{\mathrm{b}}$ & & $t_{10}=-11.81^{\mathrm{b}}$ & \\
& $P=0.846$ & & $P<0.001$ & \\
\hline
\end{tabular}

a Data not available.

b A Student's $t$ test was done to test for differences in error between model predictions of $t_{1}$ or $t_{2}$ and predictions by using average values of observed $t_{1}$ or $t_{2} ; 45$ or 65 days, respectively. on the usefulness of the model. This is not comparable with the problem of validating complex simulation models (15).

If ascospores are important in initiating light leaf spot epidemics in the autumn in the United Kingdom $(6,11,12)$, then model 1 could be used as a component of models to describe progress of light leaf spot epidemics (26) and incorporated into forecasting systems to guide control strategies. Previous work suggests that inoculum is an important component of systems to forecast the severity of light leaf spot epidemics in the United Kingdom (35). Model 1 could be used to predict the first appearance of mature apothecia on debris left after harvest of infected crops, and thus, when Pyrenopeziza brassicae ascospores will be released. This work suggests that apothecia will develop more slowly during a dry summer than during a wet summer in the United Kingdom. Based on this information, growers can decide whether they need to plough to remove the crop debris, and thus, the source of primary airborne ascospore inoculum in the autumn, to delay sowing to avoid the presence of airborne ascospores when the new crop emerges or to apply a fungicide spray in the autumn to control light leaf spot before the appearance of symptoms (8). Furthermore, during the period of stem extension in early spring, model 1 could be used to assess the risk that Pyrenopeziza brassicae ascospores will spread light leaf spot onto the pods (11). In combination with a yield loss model based on incidence of light

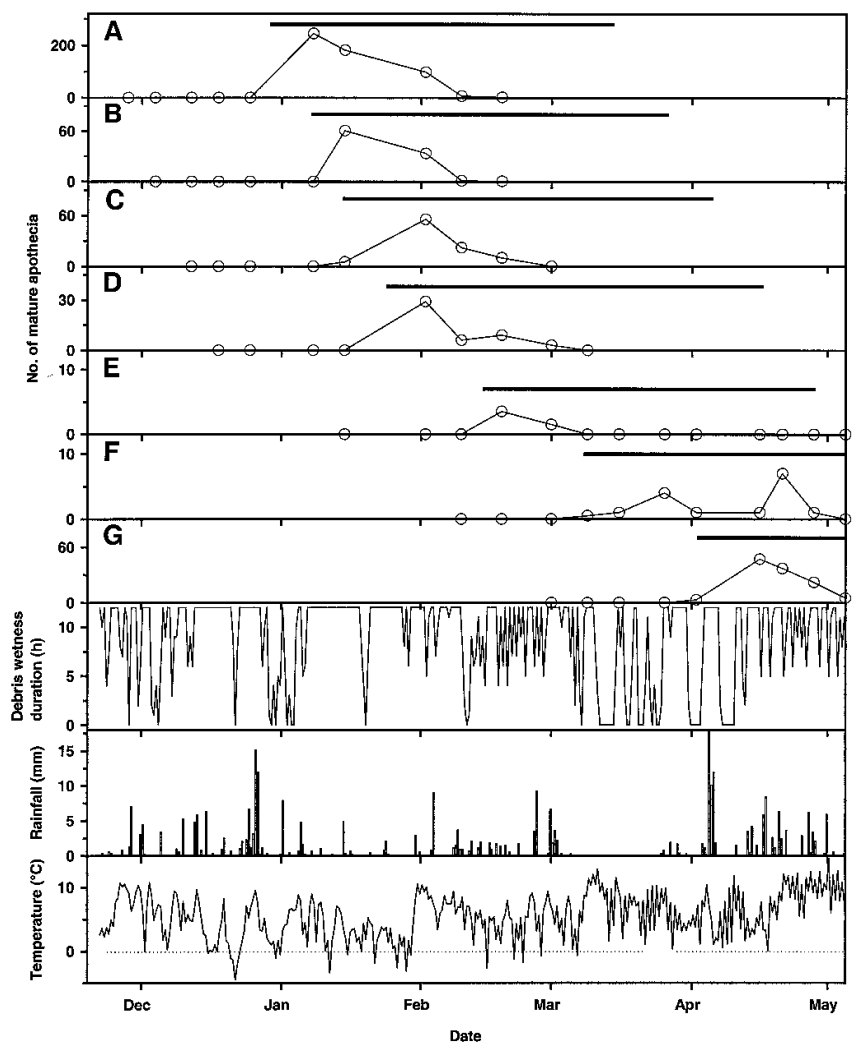

Fig. 7. Numbers of mature apothecia on oilseed rape pod debris $(0)$ that were naturally infected with Pyrenopeziza brassicae the previous season were placed on a field plot on A, 19 November 1999; B, 26 November 1999; C, 3 December 1999; D, 10 December 1999; E, 7 January 2000; F, 1 February 2000; and G, 17 February 2000. The water content of debris was measured with a debris-wetness sensor, and the number of hours when the hourly average water content was above a threshold of $0.35 \mathrm{~g}$ of water per $\mathrm{g}$ of total water content were summed to give the debris-wetness duration (h) per half day (from 8:00 to 20:00 and from 20:00 to 8:00) in relation to total rainfall (millimeters) and average temperature (Celsius). Hourly rate functions were used to predict with fluctuating temperatures $(T)$, the times of incubation $(t)$ until $50 \%$ of the maximum number of apothecia had matured $\left\{t_{1} ; 1 / t_{1, h}=\right.$ $\left.1 / 24\left[7.6+55.8(0.839)^{T}\right]\right\}$ and until $50 \%$ of the maximum number of apothecia had decayed $\left\{t_{2} ; 1 / t_{2, h}=1 / 24\left[24.2+387(0.730)^{T}\right]\right\}$, and the time interval between $t_{1}$ and $t_{2}$ (horizontal bar) was calculated. 
leaf spot at early flowering (32), this may help to guide decisions about application of fungicide sprays in spring. However, model 1 is based on measurements of temperature and debris wetness. Although it will not be difficult for growers to obtain temperature data, further research is needed to develop a simple method of measuring debris wetness on farms or to relate debris wetness to rainfall and other meteorological factors that can be routinely measured.

\section{ACKNOWLEDGMENTS}

We thank the Perry Foundation, the U.K. Ministry of Agriculture, Fisheries and Food and Biotechnology, and Biological Sciences Research Council for financial support and N. Evans and H. A. McCartney for many valuable discussions.

\section{LITERATURE CITED}

1. Abawi, G. S., and Grogan, R. G. 1975. Source of primary inoculum and effects of temperature and moisture on infection of beans by Whetzelinia sclerotiorum. Phytopathology 65:300-309.

2. Albert, R. A., Huebner, B., and Davis, L. W. 1989. Role of water activity in the spoilage of alfalfa hay. J. Dairy Sci. 72:2573-2581.

3. Amelung, D., and Daebeler, F. 1991. Occurrence of fertile apothecia and the epidemiology of Pyrenopeziza brassicae Sutton \& Rawlinson (anamorph: Cylindrosporium concentricum Grev.) in the German Democratic Republic. Int. Organ. Biol. Control Bull. 14:147-150.

4. Ball, A. M., Siddiq, A. A., and Giltrap, N. J. 1990. Assessment of benomyl resistance and mating type in field isolates of Pyrenopeziza brassicae, cause of light leaf spot of brassicas. Plant Pathol. 39:33-37.

5. Dyer, P. S., Bateman, G. L., Lucas, J. A., and Peberdy, J. F. 1994. Seasonal development of apothecia of the cereal eyespot pathogen Tapesia yallundae on straw stubble in the UK. Ann. Appl. Biol. 125:489-500.

6. Evans, N., Fitt, B. D. L., McCartney, H. A., Welham, S. J., and McRoberts, N. 1999. Sampling winter oilseed rape crops to assess incidence of light leaf spot (Pyrenopeziza brassicae) in the UK. Asp. Appl. Biol. 56:123-128.

7. Fernandes, J. M. C., Sutton, J. C., and James, T. D. W. 1991. A sensor for monitoring moisture of wheat residues: Application in ascospore maturation of Pyrenophora tritici-repentis. Plant Dis. 75:1101-1105.

8. Fitt, B. D. L., Doughty, K. J., Gladders, P., Steed, J. M., and Sutherland, K. G. 1998. Diagnosis of light leaf spot (Pyrenopeziza brassicae) on winter oilseed rape (Brassica napus) in the UK. Ann. Appl. Biol. 133:155-166.

9. Garcia, S. M., and Jones, A. L. 1993. Influence of temperature on apothecial development and ascospore discharge by Blumeriella jaapii. Plant Dis. 77:776-779.

10. Gilles, T., Ashby, A. M., Fitt, B. D. L., and Cole, T. 2001. Development of Pyrenopeziza brassicae apothecia on agar and oilseed rape debris. Mycol. Res. In press.

11. Gilles, T., Evans, N., Fitt, B. D. L., and Jeger, M. J. 2000. Epidemiology in relation to methods for forecasting light leaf spot (Pyrenopeziza brassicae) severity on winter oilseed rape (Brassica napus) in the UK. Eur. J. Plant Pathol. 106:593-605.

12. Gilles, T., and Fitt, B. D. L. 1999. Infectivity of ascospores of Pyrenopeziza brassicae on leaves and factors affecting maturation of apothecia on debris of oilseed rape. Asp. Appl. Biol. 56:61-66.

13. Gilles, T., Fitt, B. D. L., Kennedy, R., Welham, S. J., and Jeger, M. J. 2000. Effects of temperature and wetness duration on conidial infection, latent period and asexual sporulation of Pyrenopeziza brassicae on leaves of oilseed rape. Plant Pathol. 49:498-508.

14. Holtz, B. A., Michailides, T. J., and Hong, C. 1998. Development of apothecia from stone fruit infected and stromatized by Monilinia fructicola in California. Plant Dis. 82:1375-1380.

15. Jeger, M. J. 1986. The potential of analytical compared with simulation approaches to modeling plant disease epidemics. Pages 255-281 in: Plant Disease Epidemiology: Population Dynamics and Management. Macmillan Publishing Company, New York.

16. Kopmans, E. 1993. Influence of irrigation on formation of apothecia from sclerotia of the stem rot pathogen, Sclerotinia sclerotiorum. Vaxtskyddsnotiser 57:75-77.

17. Lacey, M. E., Rawlinson, C. J., and McCartney, H. A. 1987. First record of the natural occurrence in England of the teleomorph of Pyrenopeziza brassicae on oilseed rape. Trans. Br. Mycol. Soc. 89:135-140.

18. Larroche, C., Theodore, M., and Gros, J. B. 1992. Growth and sporulation behavior of Penicillium roquefortii in solid substrate fermentation: Effect of the hydric parameters of the medium. Appl. Microbiol. Biol. 38:183-187.

19. Lee, Y. S., and Huang, C. S. 1973. Effect of climatic factors on the development and discharge of ascospores of the citrus black spot fungus. J. Taiwan Agric. Res. 22:135-144.

20. Luth, P., Pfeffer, H., and Schulz, R. R. 1992. The influence of different fungus species and isolates on the formation of apothecia of Sclerotinia sclerotiorum under simulated spring conditions. Zbt. Mikrobiol. 147:368-377.

21. Majer, D., Lewis, B. G., and Mithen, R. 1998. Genetic variation among field isolates of Pyrenopeziza brassicae. Plant Pathol. 47:22-28.

22. McCartney, H. A., and Lacey, M. E. 1990. The production and release of ascospores of Pyrenopeziza brassicae on oilseed rape. Plant Pathol. 39:17-32.

23. McCartney, H. A., Lacey, M. E., and Rawlinson, C. J. 1986. Dispersal of Pyrenopeziza brassicae spores from an oil-seed rape crop. J. Agric. Sci. (Camb.) 107:299-305.

24. Nordin, K., Sigvald, R., and Svensson, C. 1992. Die Vorhersage von Rapskrebs auf Sommerraps. Z. Pflanzenkr. Pflanzenschutz 99:245-255.

25. O'Leary, A. L., and Sutton, T. B. 1986. The influence of temperature and moisture on the quantitative production of pseudothecia of Venturia inaequalis. Phytopathology 76:199-204.

26. Papastamati, K., Welham, S. J., Fitt, B. D. L., and Gladders, P. 1999. Modeling the progress of light leaf spot (Pyrenopeziza brassicae) on winter oilseed rape (Brassica napus) in relation to weather criteria. Asp. Appl. Biol. 55:49-55.

27. Pedersen, H. L., and Hockenhull, J. 1996. Effects of urea on the formation of apothecia and winter conidia of Blumeriella jaapii (cherry leaf spot) and associated microfungi on overwintered cherry leaves. Gartenbauwissenschaft 61:257-261.

28. Prados-Ligero, A. M., Gonzalez-Andujar, J. L., Melero-Vara, J. M., and Basallote-Ureba, M. J. 1998. Development of Pleospora allii on garlic debris infected by Stemphylium vesicarium. Eur. J. Plant Pathol. 104:861-870.

29. Raynal, G. 1987. Factors acting on apothecia formation of Sclerotinia trifoliorum Eriks. under controlled conditions. Agronomie 7:715-725.

30. Reiss, K., and Zinkernagel, V. 1997. Epidemiologische Untersuchungen zur Ascosporenfreisetzung von Pseudopezicula tracheiphila (MüllThurg.) Korf \& Zhuang, dem Erreger des Roten Brenners am Wein. Z. Pflanzenkr. Pflanzenschutz 104:113-125.

31. Singh, U. P., and Singh, R. B. 1987. Effect of light of different wavelengths on apothecium formation in Sclerotinia sclerotiorum. Z. Pflanzenkr. Pflanzenschutz 94:500-508.

32. Su, H., Fitt, B. D. L., Welham, S. J., Sansford, C. E., and Sutherland, K. G. 1998. Effects of light leaf spot (Pyrenopeziza brassicae) on yield loss in winter oilseed rape. Ann. Appl. Biol. 132:371-386.

33. Tippett, J. T., Crombie, D. S., and Hill, T. C. 1987. Effect of phloem water relations on the growth of Phytophthora cinnamomi in Eucalyptus marginata. Phytopathology 77:246-250.

34. Twengstrom, E., Kopmans, E., Sigvald, R., and Svensson, C. 1998. Influence of different irrigation regimes on carpogenic formation of sclerotia of Sclerotinia sclerotiorum. J. Phytopathol. 146:487-493.

35. Welham, S. J., Fitt, B. D. L., Turner, J. A., Gladders, P., and Sutherland, K. G. 1999. Relationships between regional weather and incidence of light leaf spot (Pyrenopeziza brassicae) on winter oilseed rape in England and Wales. Asp. Appl. Biol. 56:51-59. 